\title{
ARQUEOLOGÍA EN LA CUENCA INFERIOR DEL RÍO SALADO (PROVINCIA DE SANTA FE). PRIMERAS APROXIMACIONES AL ESTUDIO DE UN SITIO ARQUEOLÓGICO CON ENTERRATORIOS MÚLTIPLES
}

\author{
Archaeology in the Lower Salado River Basin (Santa Fe province). First Approach to \\ the Study of an Archaeological Site with Multiple Burials
}

\section{María Rosario Feuillet Terzaghi y Santiago L. Deluca}

\section{Resumen}

En este trabajo se da cuenta de las tareas llevadas a cabo en el sitio arqueológico Río SaladoCoronda II, en la ciudad de Santo Tomé, provincia de Santa Fe.

Los estudios realizados abren una nueva serie de expectativas arqueológicas para el área de la cuenca inferior del río Salado, la cual se mantuvo durante muchos años relegada en función de las investigaciones realizadas en los ambientes de influencia directa del río Paraná.

El hallazgo por parte de vecinos en el barrio de Villa Adelina Este de la ciudad de Santo Tomé (provincia de Santa Fe) de ítems arqueológicos, derivó en el descubrimiento de un área de enterratorios múltiples, asociada a restos materiales que sugieren un uso particular de ese espacio por parte de las sociedades que lo ocuparon en el pasado, vinculado al sistema de creencias.

Se presentan aquí los primeros resultados obtenidos del análisis del registro arqueológico del sitio mencionado.

$<$ Arqueología $><$ Cuenca Inferior del Río Salado $><$ Enterratorios $>$

\begin{abstract}
This research work sheds light on different tasks performed in Río Salado-Coronda II archaeological site, in the city of Santo Tomé, Santa Fe province.

The studies carried out attract a new series of archaeological expectations for the Lower Salado River Basin area, which had been relegated due to research done around the Parana River.

The finding of archaeological items done by neighbours from the Villa Adelina Este neighbourhood in Santo Tomé City (Santa Fe province), led to the discovery of an area of multiple burials, in which material remains suggest a particular use of the area by the societies who lived there in the past, linked to their religious system.

The first results obtained from the analysis of the archaeological record of the mentioned site are presented.
\end{abstract}

$<$ Archaeology $><$ Lower Salado Basin $><$ Multiple Burials $>$ 


\section{Introducción}

Los análisis y datos contenidos en este trabajo, forman parte de un proyecto de investigación mayor denominado "El Registro Arqueológico del Uso del Espacio en la Cuenca Inferior del Río Salado y Superior y Media del Río Coronda"; el mismo es llevado adelante por uno de los autores (MRFT), dirigido por el Lic. Carlos N. Ceruti, y a contado con financiación del Consejo Nacional de Investigaciones Científicas y Técnicas (CONICET) a través de una beca interna doctoral.

Este proyecto posee como objetivo general formular un modelo explicativo de las formas en que se relacionaron con el medioambiente y cómo utilizaron el mismo, las sociedades humanas que ocuparon durante el Holoceno tardío las cuencas de los río Salado y Coronda en su tramo inferior la primera, y superior la segunda.

El interés en el área del río Salado y Coronda surgió a partir de la carencia de estudios arqueológicos sistemáticos en la misma, lo cual representaba un vacío en el conocimiento del pasado tanto a nivel local como regional. En la historia de la arqueología del nordeste argentino y particularmente del centro-sur de la provincia de Santa Fe, los primeros estudios se mantuvieron enfocados en las zonas de influencia del río Paraná (y secundariamente, en mucho menor proporción en el río Salado), centrándose particularmente en el análisis de la cerámica (de Aparicio 1935, 1940; Badano 1940, 1957; Castellanos 1944; de Aparicio y Frenguelli 1923; Larguía de Crouzeilles 1936, 1939; Outes, 1917a y b, 1923; Torres 1907; Serrano 1931, 1954, 1972; Vignati 1923, 1925-27).

Investigaciones regionales más recientes (Ceruti 1991, 1995a; Escudero 1998; Pérez Jimeno 1999, 2002; Letieri 1999; Cocco et al. 2000; Feuillet Terzaghi 2002; Santiago 2002; Ottalagano 2002; Escudero y Feuillet Terzaghi 2004; entre otros) se orientaron hacia diversas temáticas dentro de la disciplina arqueológica. Se mantuvo, sin embargo, la vinculación fundamental con el río Paraná predominando los estudios de subsistencia-asentamiento de las sociedades cazadoras-recolectoras, en relación a la llanura aluvial del mencionado río.

El río Salado por su parte, es un importante vector que atraviesa la provincia de Santa Fe en sentido Noroeste-Sudeste. En el paraje denominado Cuatro Bocas, a la altura de la ciudad de Santo Tomé, ingresa al lecho de inundación del Paraná dando inicio al río Coronda, al que varios autores consideran simplemente la continuación del río Salado (Gollán y Lachaga 1939). En todo el sector existen muy pocos antecedentes éditos que den cuenta de investigaciones arqueológicas sistemáticas. Constituyen una excepción los trabajos de Castellanos (1924), Frenguelli (1920) y Vignati (1923; 1925 27), centrados en la confluencia del río Salado con el $\mathrm{A}^{\circ}$ Cululú (Departamento Las Colonias); su revisión por Ceruti (1995a); dos artículos sobre sitios arqueológicos ubicados en la cuenca del Coronda (Serrano 1922, 1929) y la laguna homónima (Astiz et al. 1975); las descripciones de materiales localizados en el paradero "Ombú de Basualdo" en la ciudad de Coronda (Larguía de Crouzeilles 1936) y las descripciones del sitio "Pajas Blancas” (Badano 1940; Zapata Gollán 1989). 
Al momento de inicio del proyecto en el año 2003, el área escogida para el desarrollo de esta investigación no poseía sitios localizados con exactitud, sino meras descripciones de materiales aislados encontrados durante recorridas asistemáticas, y descripción de "paraderos", como se los llamaba habitualmente, de ubicación confusa (Larguía de Crouzeilles 1936; Zapata Gollán 1989). De este modo desde los comienzos de las investigaciones hasta el momento se han relevado, prospectado y excavado más de quince sitios arqueológicos (Feuillet Terzaghi y Escudero 2010) de los cuales RSC II es uno de ellos.

\section{El sitio Río Salado-Coronda II}

El primer sitio arqueológico localizado y excavado al inicio del proyecto en el año 2003, correspondió a Río Salado-Coronda I, recuperándose principalmente en el mismo fragmentos cerámicos y escasos restos de Myocastor coypus (Feuillet Terzaghi 2004, Sartori y Feuillet Terzaghi 2007). En marzo del año 2007, vecinos del barrio Villa Adelina Este de la ciudad de Santo Tomé, dan cuenta de la presencia de fragmentos cerámicos y óseos dispersos sobre la calle Roverano a escasos doscientos metros del sitio Río Salado Coronda I. Esta situación se había producido debido a las intensas lluvias que en marzo del año mencionado provocaron la inundación de gran parte de la ciudad. El escurrimiento de las aguas en un área con gran pendiente que termina en el río, provocó el "lavado" de una vía pública de tierra, dejando expuestos los ítems mencionados.

La primera evaluación realizada en el lugar, determinó que los elementos óseos correspondían a restos esqueletales humanos, constatándose la presencia de al menos seis cráneos. Teniendo en cuenta esto y considerando que la calle es de uso público y por ella transita gran número de vehículos $\mathrm{y}$, ante el inminente riesgo de destrucción, se decidió intervenir el mismo.

RSC II se encuentra a los $31^{\circ} 41^{\prime} 53.2^{\prime \prime}$ Latitud Sur y $60^{\circ} 44^{\prime} 59^{\prime \prime}$ Longitud Oeste, sobre la margen derecha del río Salado, en un sector elevado el cual puede catalogarse como parte de la barranca aunque actualmente la misma se encuentra alterada por distintos rellenos que se realizaron a través del tiempo, con el objeto de generar una pendiente que permitiera el descenso al río (figura 1).

Originalmente en el sitio se plantearon seis cuadrículas de $2 \mathrm{~m}$ por $2 \mathrm{~m}$ cada una, denominadas alfanuméricamente (alfabéticamente de Oeste a Este y numéricamente de Sur a Norte), trazadas arbitrariamente para que los elementos expuestos coincidieran con ellas. La excavación se realizó por niveles artificiales de $5 \mathrm{~cm}$, pasándose por zaranda de $2 \mathrm{~mm}$ de malla todo el sedimento extraído.

Se excavó un área de 24 metros cuadrados, donde se localizaron los restos pertenecientes a un mínimo de 36 individuos, asociados a fragmentos de contenedores cerámicos, huesos de fauna, escasos restos de talla de instrumentos líticos y una ofrenda funeraria compuesta por un contenedor cerámico colocado boca abajo conteniendo en su interior valvas de moluscos (Dyplodon sp.). 


\section{Figura 1}

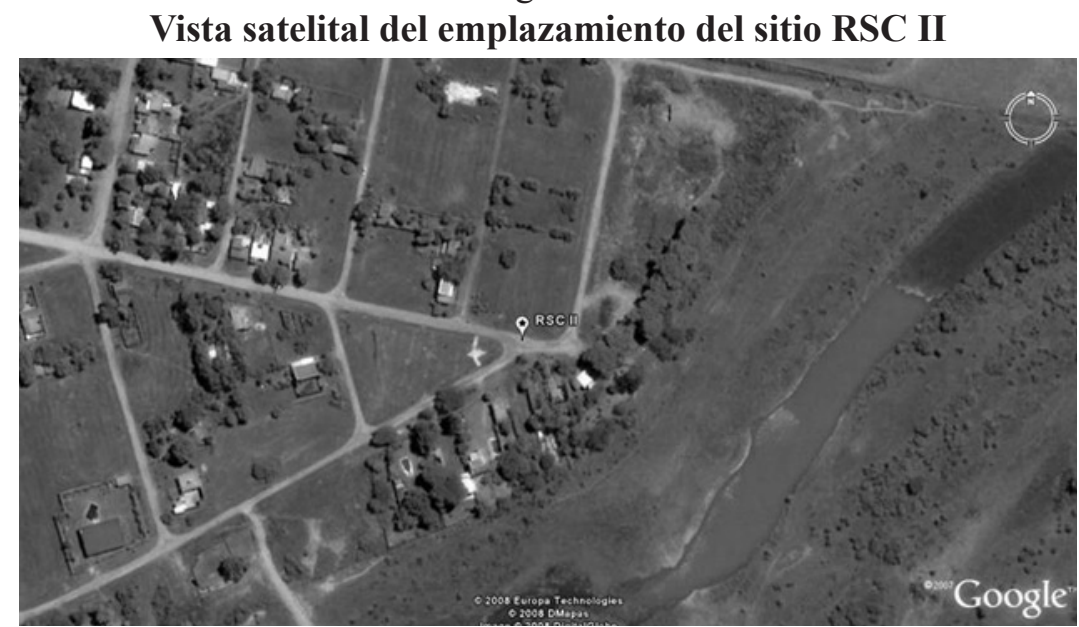

Fuente: Google Earth 2009

En diversas intervenciones posteriores, se realizaron también sondeos exploratorios a 10, 20 y 30 metros de distancia hacia el norte de la cuadrícula A2, en el terreno lindante con la calle (Figura 2). Este terreno aparentemente conserva el nivel original, topográficamente más alto, ya que hace 30 años, al abrir la calle, se usaron palas mecánicas para obtener una pendiente más suave que permitiera el descenso al río. También se realizaron sondeos en el sector inmediato al área excavada donde se colocaron postes para el cerco perimetral que se instaló con el objeto de proteger el sitio arqueológico.

Figura 2

Planta del sitio RSC II

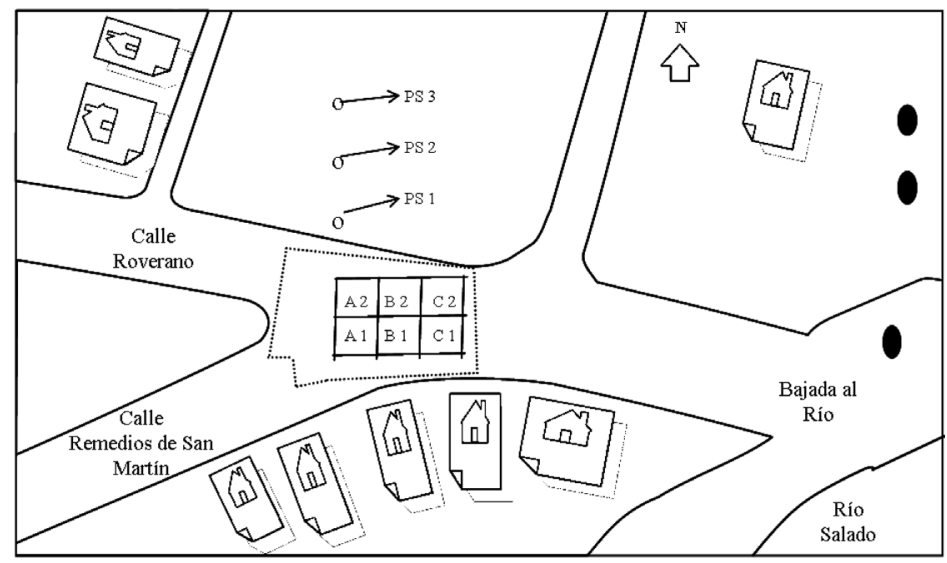

Referencias:

(i) Viviendas Árboles ……. $\begin{aligned} & \text { Sondeos sobre perimetro } \\ & \text { de vallado de protección }\end{aligned}$ 
En todos los sondeos se localizaron ítems culturales: restos de pigmentos minerales (ocre); cuentas de cerámica y roca pulida pertenecientes a objetos ornamentales (por ejemplo, collares, pulseras, tobilleras), fragmentos cerámicos de vasijas y elementos óseos faunísticos, localizándose solamente un resto lítico. En los sondeos llevados adelante sólo se localizaron restos humanos en los inmediatos al sector de excavación de las cuadrículas. Cabe destacar que los hallazgos de ítems culturales se produjeron por encima y por debajo del nivel de los enterratorios.

La datación del sitio arrojó una antigüedad de $1000 \pm 30$ años AP (UGAMS \# 02472 Radiocarbon ${ }^{13} \mathrm{C}$ Corrected Age $\mathrm{YBP} \pm 1 \mathrm{~s}$ ) realizada sobre colágeno de piezas dentarias humanas correspondientes a un enterratorio del nivel I.

En relación específicamente a las características geológicas del sitio, el mismo se emplaza sobre la costa alta del río Salado. Iriondo (com. pers.) determinó que los materiales se encuentran en la Formación San Guillermo, caracterizada por ser una formación loéssica, con presencia de arcilla y arena muy fina.

En relación al perfil estratigráfico del sitio, el mismo presenta un suelo actual con contenido de arena de un espesor de aproximadamente $25 \mathrm{~cm}$, apareciendo debajo de éste y de modo transicional la Formación San Guillermo, la cual posee un espesor de aproximadamente $80 \mathrm{~cm}$ y localizándose en ella los materiales arqueológicos. La Formación San Guillermo transicionalmente da paso a la Formación Tezanos Pinto característica ya del Holoceno Medio (Iriondo 1991).

\section{Metodología.}

Se analizaron los materiales cerámicos, arqueofaunísticos, líticos y osteológicos humanos, provenientes del sitio RSCII.

\section{Metodología de análisis osteológico humano}

En relación al análisis de los elementos óseos humanos, el mismo presentó dificultades en su tratamiento, debido por un lado al estado de conservación de la muestra, producto del contexto de depositación. RSC II al ubicarse en un ámbito urbano (particularmente sobre una calle) ha estado sometido a factores tales como tránsito de vehículos y pisoteo, lo que afectó significativamente los elementos.

Se tuvieron en cuenta los procesos tafonómicos que intervinieron en la formación del registro y que pueden presentar cambios en tres dimensiones: la de los objetos, donde los restos pueden ser sustraídos, introducidos o mantenidos en una matriz sedimentaria; la espacial, es decir si los restos migran o no; y la de las modificaciones, en donde un resto óseo puede ser modificado por agentes antrópicos o naturales o no modificado (Lyman 1994).

Los procesos explicitados en el párrafo anterior, pueden actuar de manera individual o simultánea produciendo diversos efectos en el conjunto analizado. Estos últimos se dividen en cuatro categorías básicas que son la desarticulación 
(disociación de los elementos esqueletales), la dispersión (incremento o reducción de la distancia entre las partes esqueletales), la fosilización (alteración química del hueso) y las modificaciones mecánicas (alteración de la estructura del hueso por factores físicos); todo esto deja huellas, las cuales pueden dar cuenta de los agentes que intervinieron en la formación y modificación del conjunto analizado (Lyman 2002). La identificación de las alteraciones se llevó a cabo mediante la implementación de criterios considerados diagnósticos que permitieron diferenciar cuáles son los agentes que estuvieron involucrados (Lyman 2002; Gifford 1981), de esta manera se relevaron en los elementos, los estadios de meteorización (Behrensmeyer 1978), marcas de raíces, procesos de mineralización, marcas de roedores, como así también se llevaron a cabo análisis sedimentológicos con el objeto de evaluar la acidez del suelo (Wood and Johnson 1978); estas variables fueron consideradas también para el análisis de los especímenes faunísticos.

Las estimaciones de sexo y edad en el conjunto analizado, solo pudieron realizarse en muy pocos individuos, esto se debió a que las partes consideradas diagnósticas para este tipo de análisis se encontraban en algunos casos ausentes o sumamente fragmentadas. Para la determinación sexual se tuvieron en cuenta los criterios de Buikstra and Ubelaker (1994), observándose en el cráneo las estructuras sexuales dimórficas, esto es cresta nucal, apófisis mastoides, arcos superciliares, prominencia de la glabela, y prominencia mentoniana. En relación a la determinación sexual por medio de la pelvis, ésta no pudo realizarse ya que este elemento se encontró muy fragmentado, y en algunos casos sólo se recuperaron pequeños fragmentos en los enterratorios hallados.

La determinación etaria, en la cual se observan el grado de fusión de las suturas craneanas (Buikstra and Ubelaker 1994; White and Folkens 2000), y los cambios morfológicos en la carilla de la sínfisis púbica (Todd 1920; Brooks and Suchey 1990;), en este caso se vio sumamente limitada por los motivos mencionados en relación a la preservación. Esta estimación sólo pudo efectuarse en tres individuo a través de la piezas dentales y utilizándose los criterios de Ubelaker (1989) y White and Folkens (2000) en relación al estadio de desarrollo de las piezas dentales.

En relación al contexto de depositación de los restos humanos, se tuvieron en cuenta las asociaciones con otro tipo de materiales, la presencia y/o ausencia de ofrendas funerarias, el tipo de inhumación de los restos (entierros primarios y secundarios) y patrones de enterramiento. Esto último, relacionado con el registro arqueológico en su conjunto, permitió inferir conductas relativas a las prácticas mortuorias vinculadas a aspectos simbólicos, ideológicos y de uso del espacio del grupo o grupos que ocuparon estos sitios (Carr 1995; Chapman 1995; Charles and Buikstra 1983).

\section{Metodología de análisis faunístico}

El análisis de los restos óseos faunísticos se realizó aplicando el método de numeración estadística (en el sentido de Berwick 1975), con el fin de obtener datos que 
permitieran cuantificar la muestra. El conjunto faunístico, definido como la colección de especímenes y elementos provenientes de un contexto cultural (Grayson 1984), fue analizado utilizando las etapas propuestas por Grayson (1984), Mengoni Goñalons (1988), Lyman (1994), y Salemme et al (1988), para la identificación tanto anatómica como taxonómica de la muestra.

Para la cuantificación se establecieron los índices de abundancia de cada especie y la abundancia de cada parte esqueletal de la muestra (en el sentido de Klein and Cruz Uribe 1984). Para ello se emplearon las categorías de Número de Especímenes Identificados por Taxón (NISP), y el Número Mínimo de Individuos (MNI),

La estimación etaria de las especies presentes, fue otro punto tenido en cuenta en el análisis faunístico A través de la determinación de ésta se pueden observar patrones en la selección de las presas que son utilizadas por los grupos humanos. En el conjunto analizado en este trabajo, la estimación de edad se realizó para una sola especie, $M$. coypus, ya que las partes anatómicas presentes de otros taxa identificados no se consideraron diagnósticas para este análisis. La determinación etaria de coipo fue realizada por la Lic. Julieta Sartori, teniendo en cuenta el criterio de erupción de los premolares y molares de Rusconi (1930), y el desgaste dentario (González 2005) ya que la observación de estas categorías brinda datos estimativos de la edad del animal al momento de la muerte.

Es de destacar que el criterio de erupción dentaria utilizado en este trabajo para la estimación de la edad, en relación al estado de las muestras resultó muy útil, ya que los maxilares, hemimandíbulas y dientes son los elementos, como se verá más adelante, más representados en la muestra estudiadas, sea que se hayan conservado por su alta densidad ósea y alto índice de supervivencia, o por patrones de descarte vinculados a la utilización de estos animales.

Se tuvo en cuenta en el análisis faunístico la presencia de modificaciones de carácter antrópico tales como marcas de corte y alteraciones térmicas, como así también el tipo de fracturas (Binford 1981).

\section{Metodología de análisis cerámico}

Para llevar a cabo el análisis de los materiales cerámicos se consideraron a los ítems como parte de contenedores (en el sentido de Braun 1983), y el énfasis en el estudio estuvo colocado en los aspectos tecnológicos de la manufactura (Schiffer and Skibo 1997).

La cadena operativa de la producción cerámica implica una serie de pasos necesarios para obtener un producto cuya función puede ser económica, social, ornamental, ritual, etc. (Skibo 1992). En esta cadena operativa entran en juego distintas variables, tales como la disponibilidad y la accesibilidad a las fuentes de materia prima y combustible, la experiencia y el cúmulo de conocimientos del artesano, y las características intrínsecas del grupo social involucrado. Por ejemplo el tratamiento con 
pintura y/o la aplicación de decoración incisa se encuentran vinculados a esquemas de representación, los que indicarían la utilización de los contenedores con este tipo de tratamiento fuera de la esfera tecnofuncional, destinadas a cumplir funciones vinculadas con el desempeño visual como así también tareas específicas (Skibo 1992). Asimismo, el tipo de inclusiones de la pasta estarían vinculadas intrínsecamente tanto con aspectos formales como funcionales (resistencia física y térmica de la pieza, portabilidad, entre otros).

Se tuvieron en cuenta los aspectos tecnomorfológicos considerándose una serie de etapas comprendidas dentro del proceso de manufactura cerámica, y las variables consideradas fueron: aspecto superficial del fragmento (interior y exterior), presencia/ ausencia de baño o engobe, presencia/ausencia de inclusiones, presencia/ausencia de pintura, presencia/ausencia de incisiones, presencia/ausencia de bordes, presencia/ ausencia de rodamiento y abrasión, tipo de fractura, grosor, largo, ancho, y finalmente espectro de color en superficies externas (CES), margen externo (CEM), núcleo $(\mathrm{N})$, margen interno (CIM) y superficie interna (CIS). Todas estas categorías fueron observadas a nivel macroscópico y con lupa de $10 \mathrm{X}$.

Los espectros de colores fueron relevados siguiendo los criterios del Prehistoric Ceramics Research Group (1995), quienes establecen cuatro posibles espectros a saber: Espectro 1 marrón-anaranjado-rojo; Espectro 2 rosado-amarillo-blanco; Espectro 3 blanco y Espectro 4 negro-gris.

Solo se recuperaron 8 materiales líticos en los cuales se analizaron el tipo de materia prima (para determinar las posibles localidades de aprovisionamiento y evaluar su accesibilidad), y el tamaño y presencia/ausencia de corteza, con el objeto de obtener una aproximación a las etapas involucradas en la cadena operativa (Collins 1990).

\section{Resultados}

\section{Registro bioarqueológico}

Se registraron tanto enterratorios primarios como también secundarios pertenecientes hasta el momento al menos a 36 individuos. El MNI fue calculado en base a los cráneos. Cabe destacar que el MNI seguramente sufrirá modificaciones ya que por un lado la muestra sigue en proceso de análisis, y por otro debido a que el sitio no fue excavado en su totalidad.

Las alteraciones observadas corresponden a marcas de roedores presentes sobre elementos correspondientes a tibias, fémures, húmeros ( $\mathrm{N} 47$ ), y en menor medida en elementos tales como costillas, radios, cúbitos y falanges (N 20). Se comprobó la presencia de patrones dendríticos de raíces en escasos elementos (N 37), mientras no se presenció en los elementos estadios de meteorización. La principal causa que afecta significativamente la integridad anatómica de los elementos es la fragmentación (Figura 3). Las fracturas observadas, longitudinales, horizontales y lisas son frescas, provocadas por un lado por el pisoteo y tránsito vehicular, ya que el sitio se encuentran 
en un lugar de alta actividad antrópica actual, y por otro a las fluctuaciones de humedad de los sedimentos lo que hace que los mismos se dilaten cuando están húmedos y se contraigan al perder humedad, provocando presión en los materiales que ocasiona las fracturas observadas (Klein and Cruz Uribe 1984; Johnson 1985). Los estudios sedimentológicos arrojaron valores promedio de $\mathrm{pH}(1 / 2,5)$ 6,6 (Protocolo 21028-0 GREENLAB), valor que no debería incidir de manera negativa sobre los huesos ya que no se corresponde con un ámbito de depositación ácido, sin embargo no se descarta que la presencia de arena en el sedimento puede haber contribuido con los factores antes mencionados (Davis 1989).

\section{Figura 3}

\section{Detalle de la fragmentación de los elementos óseos in situ}

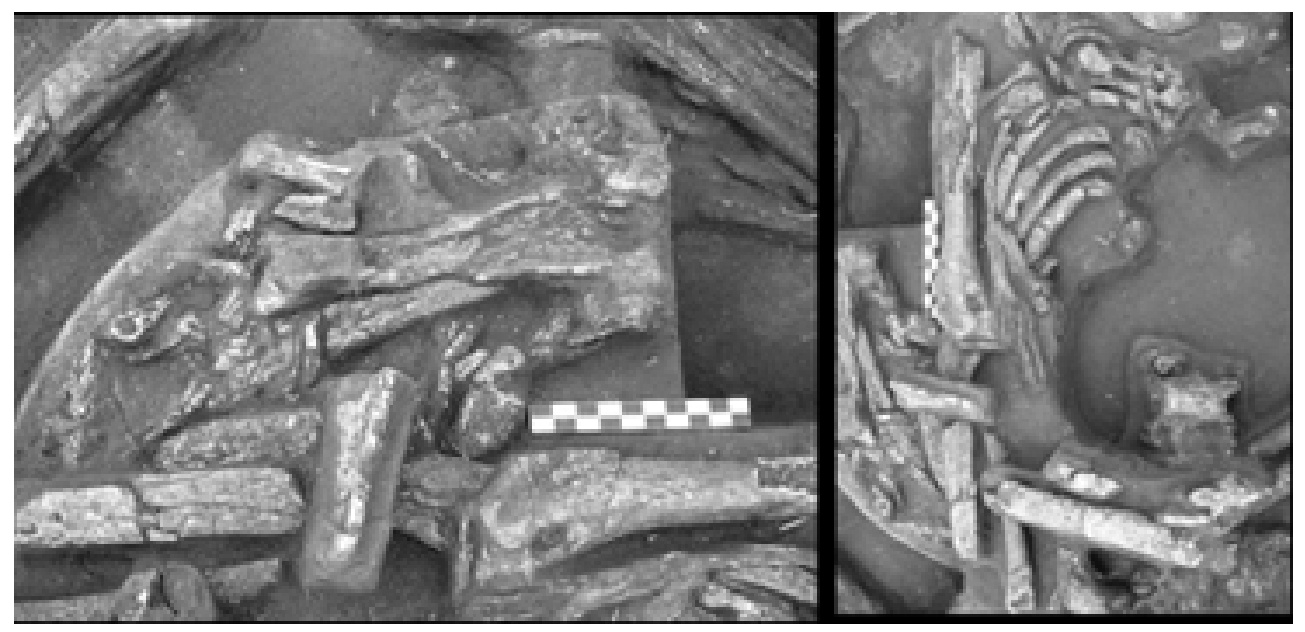

De los seis enterratorios primarios relevados, cinco de ellos están en posición decúbito dorsal extendida con sentido suroeste-noroeste, y sólo uno en posición decúbito ventral extendida y el mismo eje de depositación. Asimismo, se localizaron elementos óseos en posición anatómica cercanos a enterratorios secundarios, probablemente restos de enterratorios primarios, de los cuales sólo quedaban dos tibias y un cúbito (Figura 4).

Los entierros secundarios configuran paquetes con restos de uno a tres individuos y tres tipos de disposición: a) acumulación de huesos largos y un solo cráneo, sin orientación clara (Figura 5); b) acumulación organizada de huesos largos con la misma orientación que los entierros primarios, y el cráneo orientado al suroeste (Figura 4); c) acumulación de hasta tres cráneos, con escasa presencia de huesos largos, con eje suroeste-noreste (Figura 6). 
Feuillet Terzaghi y Deluca. Enterratorios múltiples en la cuenca inferior del río Salado

\section{Figura 4}

\section{Enterratorio secundario}

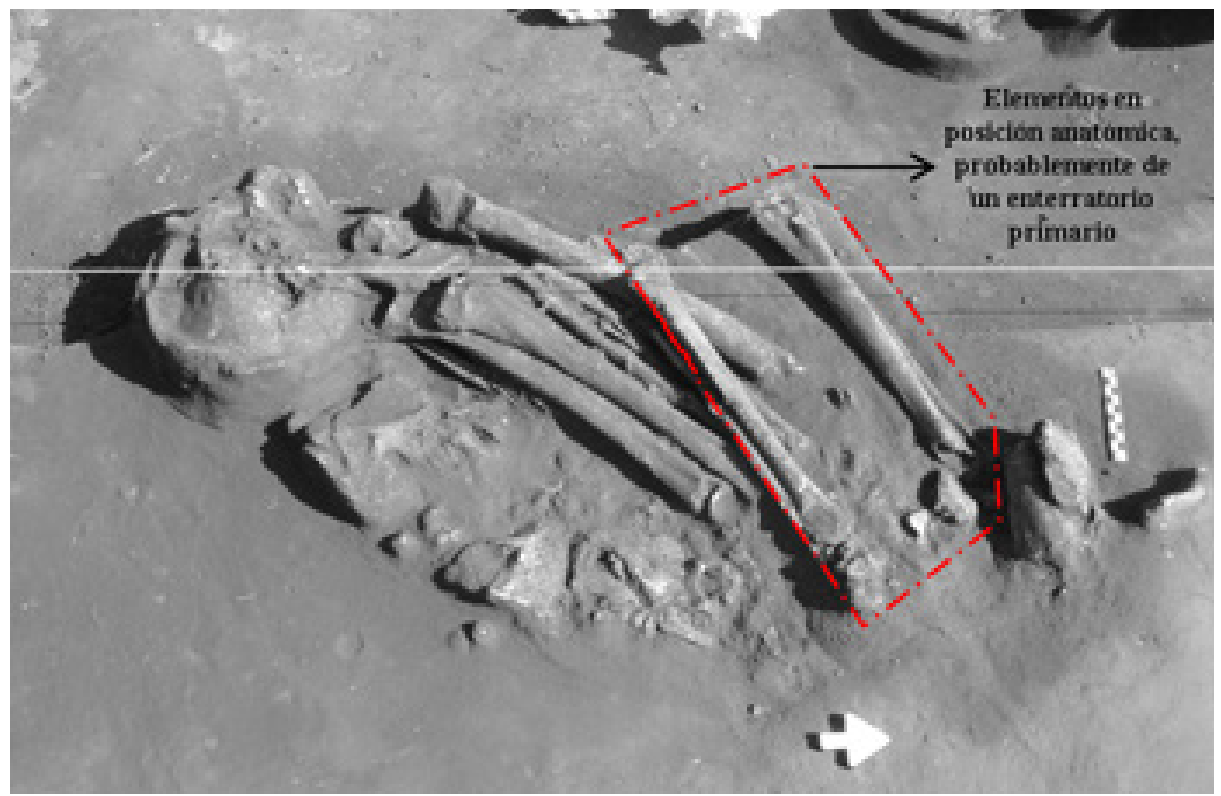

Con distribución de huesos largos y un sólo cráneo en la misma dirección que los enterratorios primarios, y el cráneo al suroeste. Nótese la presencia sobre el enterratorios secundario de dos tibias, calcáneos y tarsianos en posición anatómica, probablemente restos de un enterratorio primario.

\section{Figura 5}

\section{Enterratorio secundario}

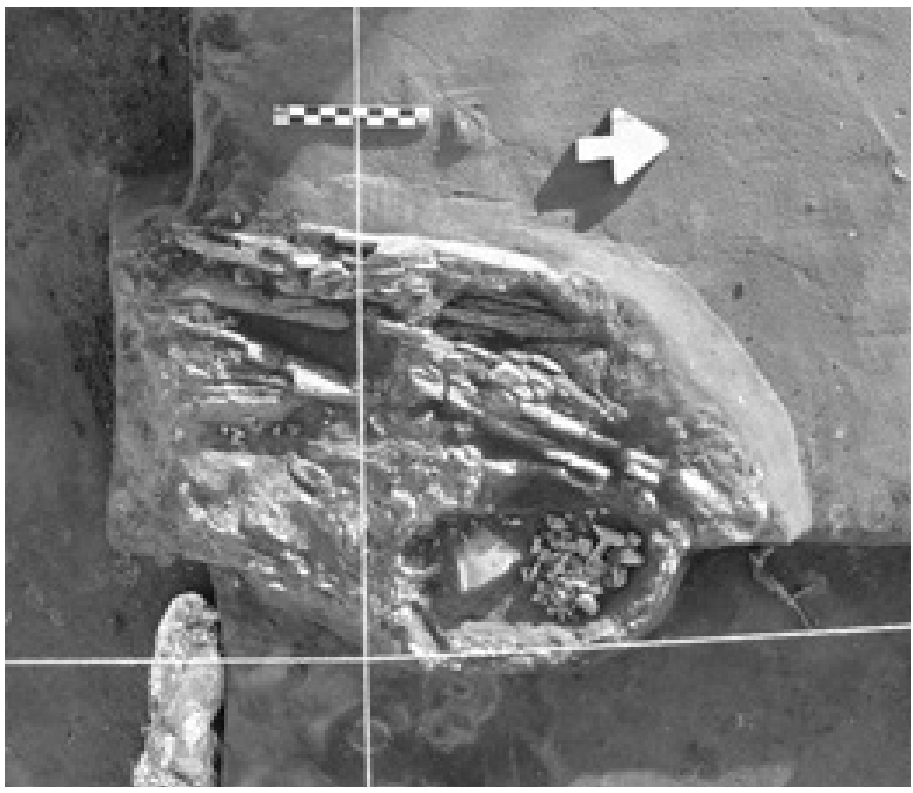

Con distribución de huesos largos y un solo cráneo sin claro patrón 
Figura 6

\section{Enterratorio secundario}

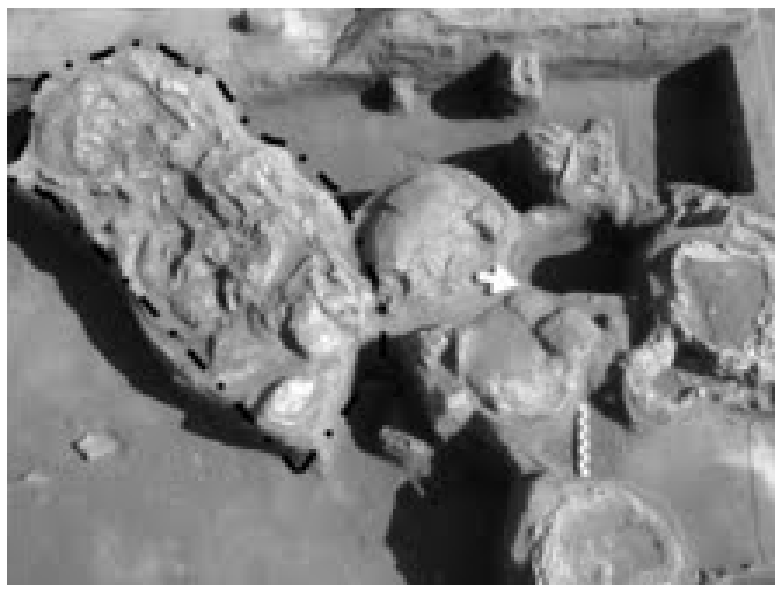

Compuesto por tres cráneos y escasos huesos largos en dirección sudoeste-noreste

Algunos enterratorios se superponen parcialmente, pero al parecer esta disposición no fue intencional sino provocada por desplazamientos como consecuencia del tránsito de vehículos. Los enterratorios se presentan a diversas profundidades, y si bien el fechado obtenido arrojó como resultado $1000 \pm 30$ años AP (UGAMS \# 02472), el mismo corresponde al nivel I de la excavación (profundidad real de $12 \mathrm{~cm}$ ) por lo que no se descarta la posibilidad de que los individuos hayan sido depositados en momentos temporales diferentes. Al momento de redacción de este trabajo se esperaban los resultados de tres dataciones más realizadas sobre elementos óseos de enterratorios pertenecientes a los niveles II, III y IV de excavación, lo cual confirmará o refutará este tópico a futuro.

Asociado al contexto de los enterratorios se localizó una ofrenda funeraria, compuesta por una vasija cerámica, colocada boca abajo, y en cuyo interior se encontraron valvas de Diplodon sp., no pudiendo establecerse la asociación directa de este ajuar a ninguno de los esqueletos debido a la dispersión y fragmentación de los elementos en el contexto inmediato (Figura 7). Por otra parte se relevó asociado a los enterratorios espículas de carbón y ocre.

Como se mencionó al principio del trabajo sobre piezas dentarias correspondientes a un cráneo del enterratorio 8, provenientes del nivel I, la datación por AMS, y el análisis de $\delta^{13} \mathrm{C}_{\mathrm{co}}(\%)$, arrojaron una antigüedad de $1000 \pm 30$ años $\mathrm{AP}$ (UGAMS \# 02472 Radiocarbon ${ }^{13} \mathrm{C}$ Corrected Age $\mathrm{YBP} \pm 1 \mathrm{~s}$ ), mientras que el valor obtenido de de $\delta^{13} \mathrm{C}_{\mathrm{co}}(\%)$, fue de $-15,6$, no contándose aún con los valores de $\mathrm{C}: \mathrm{N}$, ya que los elementos remitidos no poseían colágeno suficiente para la determinación de estos valores. En principio este valor no estaría dentro de los esperables para sociedades cazadoras-recolectoras, ya que el promedio para estas poblaciones muestran un valor medio de ${ }^{13} \mathrm{C}_{\mathrm{co}}-19,08 \pm 1,18 \%$ (Loponte y Acosta 2008). 
Figura 7

Vista de la ofrenda in situ

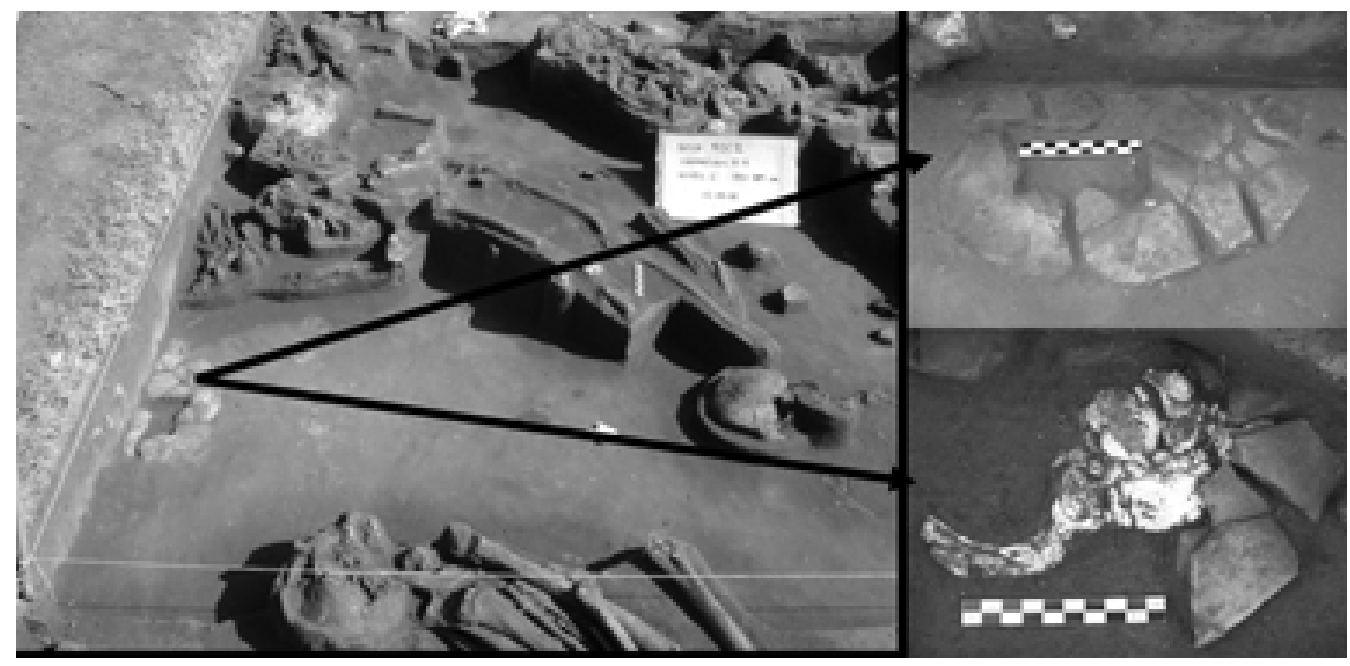

Detalles de la misma antes y después de ser excavada, nótese la presencia de valvas en su interior

En cuanto a la estimación sexual y etaria, la misma se realizó teniendo en cuenta la metodología explicitada precedentemente y sólo se pudo establecer la estimación sexual para tres individuos masculinos. Los resultados obtenidos, fueron a partir del análisis realizado sobre la morfología craneal, no pudiéndose estimar en el resto de la muestra, debido a que los sectores diagnósticos para la estimación (esto es, cresta nucal, apófisis mastoides, arcos superciliares, prominencia de la glabela, y prominencia mentoniana) presentaban alteraciones que impidieron la observación de estos puntos. Las alteraciones se corresponden con ausencia de mandíbulas, fragmentación y/o alteración del tejido óseo de los arcos superciliares, alteración por fragmentación o abrasión de la cresta nucal, ausencia de los elementos óseos nasales que impidieron observar la prominencia de la glabela. En algunos casos se pudo observar hasta tres de los indicadores, pero no se consideraron representativos para esta etapa del análisis. Se prevé a futuro interrelacionar los resultados obtenidos en los casos que no se pudieron contabilizar la totalidad de los indicadores, con datos que provengan del análisis del resto de los elementos esqueletales, los que si bien se encuentran fragmentados, están siendo sometidos a trabajos de remontaje.

Por otra parte la estimación etaria solo pudo realizarse hasta el momento para tres individuos, a través del análisis de las piezas dentales siguiendo los criterios de Ubelaker (1989) y la adaptación de los mismos por White and Folken (2000). De los tres individuos uno corresponde a un sujeto juvenil con una edad estimada de $15 \pm 3$ años, mientras que los dos restantes, de acuerdo al grado de erupción de los terceros molares y el desgaste observado se corresponden con individuos con un rango etario de entre 24 y 30 años. La estimación etaria a partir de la observación de las suturas 
craneales se vio afectada por el estado de fragmentación de los cráneos, los que si bien en algunos casos fueron remontados, el estado de la superficie cortical impidió la observación de este atributo. En relación a la observación de la superficie de la sínfisis púbica para la determinación etaria, esta se encuentra ausente en un gran porcentaje de la muestra, mientras que en aquellos casos que se cuenta con restos de coxales los mismos corresponden a fragmentos de crestas ilíacas.

Cabe destacar aquíque los elementos presentan una superficie sumamente friable, lo que dificulta su limpieza y manipulación, por lo que se implementaron estrategias de consolidación y preservación en ellos haciendo que las tareas de identificación se vean demoradas en función del tratamiento realizado para la preservación de los mismos. En este sentido la información derivada del análisis de los elementos óseos humanos se incrementara a futuro en cuanto se terminen con las tareas de consolidación y se pueda proceder a los análisis de determinación de edad y sexo.

\section{Registro arqueofaunistico}

La muestra arqueofaunística para este sitio es pequeña; del volumen total excavado $\left(13,23 \mathrm{~m}^{3}\right), 5,43 \mathrm{~m}^{3}$ corresponden al área de enterratorios múltiples, siendo los restantes $7,8 \mathrm{~m}^{3}$ provenientes de los pozos de sondeos y cuadrículas no asociadas al primer sector mencionado.

Los datos obtenidos del registro arqueofaunístico, en primer lugar muestran una escasa presencia de fauna (NISP 223). Del total de la muestra, $126(56,50 \%)$ especímenes fueron asignados a la clase Mammalia mientras que 45 (20,18\%) corresponden a la clase Peces y $52(23,32 \%)$ son indeterminados.

Del total del NISP para Mammalia $(\mathrm{N}=126), 67$ pudieron ser asignados a categorías más subordinadas, quedando los restantes 59 como Mammalia indeterminada. Pudieron identificarse tres Órdenes: Artiodactyla con un NISP de 11 (8,73\%), Rodentia con un NISP de 54 (42,86\%) siendo el orden más representado, y finalmente Cingulata con un NISP de 2 (1,59\%), siendo el menos representado.

Dentro de los Órdenes identificados pudieron establecerse categorías más específicas tanto a nivel familia, como género-especie. Las familias presentes en los sitios estudiados corresponden a Cervidae (NISP 1), Bovidae (NISP 10), Myocastoridae (NISP 24), Cricetidae (NISP 30). Mientras que a nivel género-especie pudieron ser identificados: $M$. coypus (coipo o falsa nutria) con un NISP de 24 y un MNI de 2 (Tabla 1), y Bos Taurus (vaca) con un NISP de 11 y un MNI de 1. Esta especie fue determinada a partir de fragmentos de tibia y radio los que presentan huellas de sierra eléctrica, si bien este taxón no tiene implicancia para la interpretación del uso de este espacio en el pasado, brinda datos en relación a la alteración sufrida por el registro arqueológico (Feuillet Terzaghi 2009). Todos los restos correspondientes a Bos Taurus fueron recuperados en la nivelación y en el techo del nivel I (correspondientes a $5 \mathrm{~cm}$ de profundidad real). 
Tabla 1, 2 y 3. Elementos determinados de Myocastor coipus, MNI y MNE Tabla 1

NISP y NISP \% por Clase

\begin{tabular}{|l|c|c|}
\hline CLASE & NISP & NISP \% \\
\hline Mammalia & 126 & $56,50 \%$ \\
\hline Peces & 45 & $20,18 \%$ \\
\hline Indet & 52 & $23,32 \%$ \\
\hline TOTAL & 223 & $100 \%$ \\
\hline
\end{tabular}

Tabla 2

NISP y NISP \% por órdenes dentro de la clase Mammalia

\begin{tabular}{|l|c|c|}
\hline \multicolumn{1}{|c|}{ ORDEN } & NISP & NISP \% \\
\hline Artyodactila & 11 & 8,73 \\
\hline Rodentia & 54 & 42,86 \\
\hline Cingulata & 2 & 1,59 \\
\hline Indet. & 59 & 46,82 \\
\hline Total & 126 & $100 \%$ \\
\hline
\end{tabular}

Tabla 3

Elementos determinados de Myocastor coipus, MNI y MNE

\begin{tabular}{|l|l|c|c|c|c|}
\hline \multicolumn{1}{|c|}{ Elemento } & Izquierdo & Derecho & Indet & MNI & MNE \\
\hline Esmalte incisivo frag. & & & 8 & 1 & 8 \\
\hline Frag. Esmalte Molar & & & 2 & 1 & 2 \\
\hline Molar & & & 7 & 1 & 7 \\
\hline Hemimandíbula frag. & & 2 & 1 & 2 & 3 \\
\hline Vértebra caudal & & & 2 & 1 & 2 \\
\hline Cuerpo vertebral & & & 2 & 1 & 2 \\
\hline
\end{tabular}

La representatividad de $M$. coypus se encuentra dada por elementos esqueletales pertenecientes al cráneo, lo que es significativo, ya que usualmente este taxón suele encontrarse representado por la mayoría de sus componentes esqueletales en sitios localizados en el área (Feuillet Terzaghi 2002, Feuillet Terzaghi y Escudero 2011).

Otro aspecto relevado para Myocastor coypus, fue el rango etario de de los animales presentes en el registro. De este modo, utilizando la metodología explicitada en la sección anterior, los ejemplares presentes corresponden al rango juvenil-subadulto, estimado a partir de los segundos molares. Si bien sólo pudo establecerse el rango en 
estos elementos es significativa esta representación en el contexto del sitio, ya que los elementos de este taxón provienen exclusivamente del contexto de inhumación, no encontrándose representado este taxón en los pozos de sondeo, ni en las cuadrículas realizadas fuera del área de enterratorios. Por otra parte no se presenció in situ rastros de cuevas o madrigueras realizadas por roedores.

Un punto interesante a ser considerado para $M$. coipus teniendo en cuenta el tipo de elementos recuperados y el rango etario establecido para esta especie, sumado al contexto de recuperación, y su asociación a restos de peces quemados (ver más adelante) espículas de carbón y ocre, es que los mismos estén reflejando algún tipo de comportamiento en relación a este taxón y las prácticas mortuorias. Se espera que nuevos datos provenientes de la investigación en curso puedan arrojar luz sobre este tópico.

La familia Crucetead con un NISP de 30 , se encuentra representada mayoritariamente por hemimandíbulas, incisivos y vértebras. Teniendo en cuenta el alto grado de fragmentación del conjunto y la gran cantidad de especies para el área, los elementos sólo fueron asignados al nivel familia. E1 75\% de los elementos de este taxón proviene de los pozos de sondeo y en lo que respecta a las vértebras todas se hallaron en el pozo de sondeo 1.

En relación a los peces que cuentan con un NISP de 45, la identificación taxonómica se realizó a nivel clase y subclase, de esta manera se identificó la Clase Teleostomi, Subclase Actinopterygii (Sartori 2008). Los especímenes correspondientes a estas categorías, se encontraban fragmentados, no superando ninguno de ellos los $2 \mathrm{~cm}$ de largo. Los elementos identificados para este taxón corresponden a vértebras, costilla, rayo pectoral y fragmentos de cráneo, quedando cuatro especímenes indeterminados pudiendo ser clasificados como restos de peces. Si bien sólo se pudieron establecer categorías amplias en la identificación taxonómica de esta clase, el tamaño de las vértebras no supera los $5 \mathrm{~mm}$ de diámetro, por lo que se podría asumir que corresponden a peces de pequeño porte. El MNI no fue calculado debido a la baja proporción del conjunto analizado, pero teniendo en cuenta que los individuos de esta clase y subclase poseen entre 28 y 44 vértebras, se tendría representado en el registro al menos un individuo. Cabe destacar que este número no posee implicancia estadística para el conjunto muestreado, sólo fue tenido en cuenta para demostrar la baja representatividad de esta especie en el registro.

Las modificaciones observadas en las superficies óseas de la muestra faunística corresponden a manchas de manganeso, las que afectaron el 16,5\% ( $\mathrm{N}=33)$ del NISP total y son típicas de ambiente húmedos (Gifford 1981). En relación a la presencia de huellas, éstas se relevaron únicamente en especímenes pertenecientes a Bos taurus, las cuales corresponden a huellas de sierra eléctrica y se encuentran en un 100\% del NISP de este taxón. Ninguno de los especímenes recuperados hasta el momento y pertenecientes al contexto arqueológico presentó huellas de corte, lo cual puede deberse por un lado al grado de fragmentación de la muestra lo que dificulta en muchos casos la observación de este carácter, o a que los especímenes no posean este tipo de huellas (Sartori 2008). 
El35\% del NISP total de la muestra faunística presenta alteraciones térmicas. Las mismas se pueden relevar por la coloración diferencial que presentan los especímenes, por lo que este carácter no se vio afectado para su relevamiento por la fragmentación. La presencia de alteraciones térmicas se predominantemente en la Clase Peces $(\mathrm{N}=30)$ por sobre Mammalia ( $\mathrm{N}=18)$. En la Clase Mammalia las termoalteraciones se presentan en especímenes que no pudieron ser asignados a niveles específicos de identificación, con la excepción de un fragmento de cóndilo de metapodio que fue asignado a Cervidae y una placa de banda móvil que corresponde a Dasipodidae.

El 73\% del NISP de la Clase Peces $(\mathrm{N}=30)$ presenta alteraciones térmicas, las cuales se evidencian en vértebras, fragmentos de cráneo, rayo pectoral y costilla. Si bien como se mencionó anteriormente para esta Clase, el número de especímenes recuperados hasta el momento no presenta relevancia para interpretaciones vinculadas al consumo, al igual que con M. coipus, no se descarta que esta Clase tenga implicancias conductuales vinculadas a la esfera simbólica, ya que la mayoría de los especímenes que presentan alteración térmica (el $80 \%$ ) fueron recuperados del contexto funerario, asociados a espículas de carbón y ocre vinculados a los enterratorios.

En relación a la meteorización, marcas de carnívoros, de roedores y raíces, ninguno de estos agentes tuvo incidencia en la muestra observada. La migración vertical no tuvo incidencia en el sitio, sólo fueron registrados 11 especímenes actuales en la nivelación que no se encontraban insertos en la matriz sedimentaria.

El estado fragmentario de la colección osteológica, tanto humana como faunística, se produjo fundamentalmente por el pisoteo de personas y arreo de ganado, tránsito vehicular, y dilatación y contracción sedimentaria producto de las fluctuaciones en los niveles de humedad del mismo. El pisoteo y tránsito vehicular actuó más de 30 años sobre el sitio, ya que el mismo se encuentra en una calle de tierra pública que desemboca sobre el río Salado, siendo la única vía de acceso directo a la costa. Los materiales arqueológicos se encuentran a una profundidad de entre 0 y $20 \mathrm{~cm}$, por lo que la incidencia de los factores mencionados fue directa.

A diferencia de los pozos de sondeo realizados en las inmediaciones, el área de enterratorios presenta su perfil estratigráfico alterado, ya que cuando se niveló el terreno para abrir la calle se decapitó el suelo actual y parte de la Fm. San Guillermo, removiéndose casi $75 \mathrm{~cm}$ de matriz sedimentaria, en relación al nivel original del terreno. Debido a esto, los materiales osteológicos humanos se encuentran casi en superficie sufriendo las alteraciones mencionadas, mientras que en las áreas circundantes los ítems culturales (mayoritariamente fragmentos cerámicos y muy escasos restos faunísticos) fueron recuperados a mayor profundidad (respecto al terreno actual) y sin evidencias de fracturas frescas.

\section{Registro cerámico}

Se analizó el total de los fragmentos cerámicos recuperados, estudiándose 219 fragmentos de los cuales 72 corresponden a tiestos delgados ( 0 a $5 \mathrm{~mm}$ de espesor), 
129 a medianos (5.1 a $10 \mathrm{~mm}$ de espesor), 15 a los gruesos (10.1 a $15 \mathrm{~mm}$ de espesor) y tres a los muy gruesos (15 a $\mathrm{nn} \mathrm{mm}$ de espesor); de esta manera el mayor porcentaje de los tiestos son medianos, siguiéndole en orden los delgados, gruesos y muy gruesos.

El tipo de fracturas predominantes son las regulares con un total de 123 tiestos de los cuales 44 son delgados, 69 medianos, nueve gruesos y uno muy gruesos. En relación a las fracturas irregulares, el total es de 96 fragmentos, de los cuales 28 son delgados, 60 medianos, seis gruesos y dos muy gruesos. El tipo de fracturas se encuentra íntimamente vinculado al tipo de cocción y por ende a los espectros de colores presentes producto también de la temperatura, el tiempo, y el tipo de cocción, sea ésta oxidante o reductora. En este sentido es variable la presencia de los espectros de acuerdo al sector del fragmento que se trate.

De este modo para los ítems cerámicos delgados hay una preponderancia del espectro 1 (marrón, naranja, rojo) para las superficies externas e internas, mientras que decae la misma para los márgenes externos e internos y núcleo, donde se da una supremacía del espectro 4 (negro, gris). Sólo seis tiestos de los delgados presentan una cocción oxidante completa, mientras que a los restantes les corresponde una cocción oxidante incompleta.

Los tiestos categorizados como "medianos", presentan una preponderancia del espectro 1 para las caras internas y externas, decreciendo el mismo para márgenes internos, externos y núcleo. No obstante esto, un número significativo de tiestos presenta el espectro 1 en márgenes internos y externos $(\mathrm{N}=40)$, mientras que 16 fragmentos presentan el espectro mencionado para todos los sectores. En relación al núcleo, éste se presenta como reductor (espectro 4) para la mayoría de la muestra de medianos con una representación de 113 sobre un total de 129 elementos cerámicos. Los espectros 2 (amarillo, blanco, rosado) y 3 (blanco) no se encuentran representados en los medianos.

Dentro de los gruesos, que se encuentran representados por un $\mathrm{N}$ de 15 , el espectro de color predominante para las superficies externas e internas sigue siendo el 1, manteniéndose relativamente estable esta recurrencia para los márgenes tanto internos como externos, mientras que el núcleo presenta el espectro mencionado en 7 restos cerámicos, mientras que los restantes 8 evidencian el espectro 4. En relación a los espectros 2 y 3 también se encuentran ausentes en los gruesos.

Finalmente los tiestos atribuidos a los muy gruesos, con sólo una representación de tres, presenta el espectro 1 en dos de los fragmentos en todos sus sectores, mientras que el tercero evidencia el espectro 4 en los márgenes internos y externos, núcleo y superficie externa, mientras que el espectro 1 se da en la superficie interna, que es la que presenta la aplicación de baño/engobe

En síntesis el espectro predominante para superficies internas y externas, así como para márgenes internos y externos es el espectro 1 , mientras que para el núcleo la relación se invierte y predomina el espectro 4.

Se observaron inclusiones en la pasta de 171 fragmentos del total, mientras que el aspecto superficial predominante para la muestra es el regular, observándose 
en 194 tiestos. El aspecto superficial, en pastas con antiplástico, suele ser función del tamaño de los clastos y de la técnica de amasado (óptima o deficiente). Si los clastos son grandes, la pasta está mal amasada y se quiere elaborar un contenedor de paredes finas, provocarán irregularidades en la superficie. El aspecto, entonces, estará determinado por la habilidad del alfarero y las elecciones que realice dependiendo del producto que quiera obtener (Schiffer and Skibo 1997). Para el caso estudiado, la preponderancia de paredes lisas es consecuencia de la selección de antiplástico de pequeñas dimensiones, integrado a la arcilla mediante una buena técnica de amasado.

Para que se produzcan los patrones evidenciados en los tiestos, el tipo de cocción puede haberse producido en una atmósfera con baja circulación de oxígeno y alta temperatura, para aquellos contenedores de fracturas regulares, mientras que poco tiempo de exposición al calor o baja temperatura en conjunto con escasa circulación de oxígeno pudo darse para aquéllos materiales de fracturas irregulares.

Un aspecto importante que se dejó de lado hasta aquí fueron los tratamientos vinculados a los atributos visuales, y la presencia o no de fragmentos de bordes de contenedores. En este sentido los resultados obtenidos sobre un total de 219 tiestos muestran que 53 corresponden a restos de bordes. En términos generales, y más allá de estar representados los bordes en categorías de espesor diferentes, el rango de los mismos varía entre los $5 \mathrm{~mm}$ y $16 \mathrm{~mm}$.

Dentro del total de los tiestos con bordes $(\mathrm{N}=53)$, en 23 de ellos se observan algún tipo de tratamiento -pintura roja o decoración incisa-, produciéndose en algunos de ellos combinaciones entre la aplicación de pintura (que siempre es roja) con incisiones; mientras que dentro del conjunto de fragmentos que no corresponden a bordes $(\mathrm{N}=166)$ si bien aparece la pintura o el inciso en 31 tiestos, la combinación de ambos se da en un solo tiesto (Gráfico 1).

\section{Porcentajes de aplicación y combinación de pintura e inciso en bordes y fragmentos}

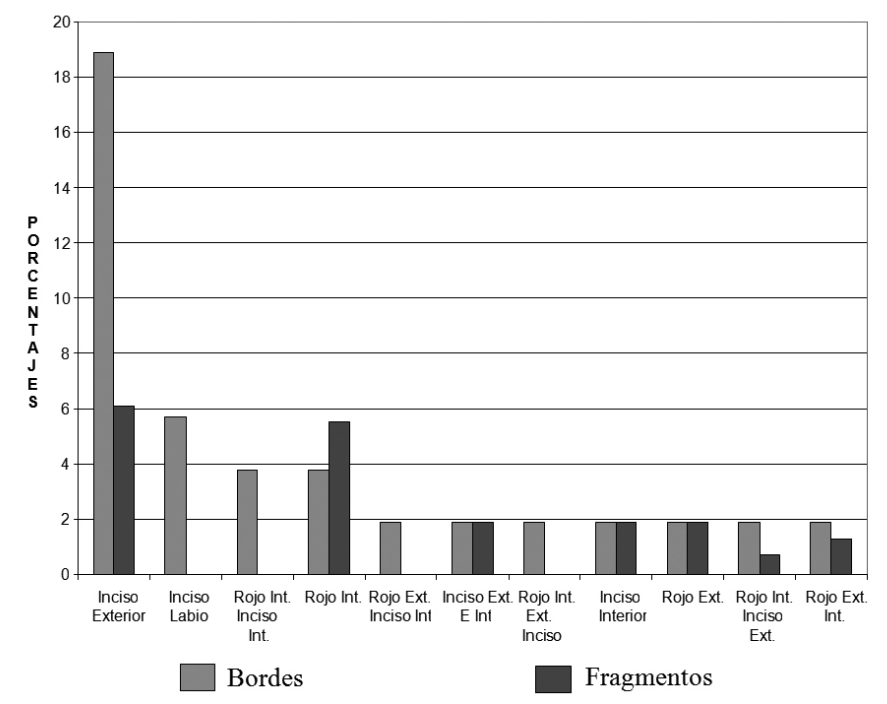


Los tratamientos mencionados son considerados como particularidades que no se encuentran dentro de la esfera tecnofuncional de los contenedores, considerándose atributos secundarios de desempeño (Skibo 1992); los mismos también dependen de la experiencia y el conocimiento del artesano, los cuales son factores causales en la variabilidad del diseño (Schiffer y Skibo 1997). La combinación de técnicas de decoración, en este caso pintura e inciso, se dan predominantemente sobre los bordes. Esta variación en el diseño se corresponde con características físicas observables y por lo tanto quizás al reconocimiento de la funcionalidad del contenedor, la cual pudo haber estado vinculada al sistema ideacional del grupo que lo produjo.

\section{Registro lítico}

Se recuperaron diez restos líticos, y si bien se trata de una muestra ínfima, la presencia de los mismos no deja de ser interesante ya que la provincia de Santa $\mathrm{Fe}$ carece de afloramientos rocosos, con lo cual el hallazgo de este tipo de evidencia es relevante en tanto que se consideran recursos críticos.

La muestra está compuesta por la presencia de cuatro tipos de materia prima, éstas son xilópalo $(\mathrm{N}=5)$, arenisca $(\mathrm{N}=3)$, ópalo $(\mathrm{N}=1)$, y calcedonia $(\mathrm{N}=1)$.

En relación a los tamaños de las mismas, se estableció un rango arbitrario: 0 a 5 mm: muy pequeño (MP); 5,1 a $10 \mathrm{~mm}$ : pequeño (P); 10,1 a $15 \mathrm{~mm}$ : mediano (Me); 15,1 a $20 \mathrm{~mm}$ : mediano grande (Me G); 20,1 a $25 \mathrm{~mm}$ : grande $(\mathrm{G}) ; 25,1$ a $30 \mathrm{~mm}$ : grande más $(\mathrm{G}+)$, y 30 a NN: muy grande. De esta manera, el xilópalo es la materia prima más representada, con una lasca perteneciente a la categoría Muy Pequeña, dos lascas Pequeño, y dos lascas a la categoría Mediano Grande. Del total de las areniscas, una de ellas es Mediano mientras que las dos restantes son Mediano Grande. La calcedonia se encuentra representada por una lasca Grande, mientras que el ópalo corresponde a la categoría Grande Más.

Los pesos de las materias primas no superan los 5 gramos en ningún caso, exceptuando el resto de ópalo, el cual corresponde a un rodado con bulbo y ondas de percusión sobre un lateral, conservando parte de su corteza en la cara posterior, y que pesa 30 gramos.

El total de los materiales exceptuando el rodado, se pueden considerar como desechos de talla (en el sentido de Aschero 1983). En relación específicamente a las materias primas presentes, los xilópalos y areniscas pueden localizarse en los afloramientos rocosos de las barrancas de la margen izquierda del río Paraná, al tiempo que las areniscas se presentan en las "Tierras Altas" del centro sur de Corrientes (Hocsman 1999). La Formación Ituzaingó es un afloramientos terciario que se presenta en las barrancas de la margen izquierda del río Paraná en Entre Ríos, y donde se dan areniscas de variados grados de coherencia, desde friables a muy duras, presentando una gama de colores entre los amarillos, ocres y rojizos. Por otra parte los xilópalos 
también son característicos de esta formación (Hocsman 1999). Las areniscas también aparecen en la provincia de Corrientes en la Formación Solari y pueden ser de tonalidad amarillenta, aunque frecuentemente presentan un tono rosado a rojizo

Por otra parte los ópalos y calcedonias pueden proceder del río Uruguay (Ceruti 1991, 1995b), o de la zona de Córdoba, más precisamente al sur de la Sierra de Comechingones, de las cercanías de las localidades de Achiras y Cuatro Vientos. (Austral y Rocchietti 1995).

De este modo las materias primas recuperadas tendrían dos orígenes posibles, Entre Ríos o Córdoba, sean que los grupos en partidas logísticas hayan buscado estos litos, o bien por intercambio.

\section{Consideraciones Finales}

Teniendo en cuenta lo expresado hasta aquí, en primer lugar se puede decir que RSC II presenta alteraciones importantes en relación a la conservación de los elementos óseos (sean estos humanos o faunísticos). Los datos relevados demuestran que los materiales localizados se encuentran sumamente fragmentados, producto de la localización de los sitios en contextos urbanos, donde el pisoteo, el tránsito vehicular y el paso de ganado, provocó la rotura de los ítems, y en el caso de los materiales óseos humanos su desplazamiento horizontal dentro del sedimento que los contenía, alterando la disposición de los enterratorios primarios y secundarios.

Por otra parte es probable que los procesos diagenéticos, hayan influido en la preservación de la muestra observada, ya que se trata de un sedimento de características loéssicas, con presencia de arena, lo que no favorece la preservación ósea (Davis 1989).

La recurrente presencia de enterratorios tanto primarios $(\mathrm{N}=9)$ como secundarios $(\mathrm{N}=25)$, con un MNI establecido hasta el momento de por lo menos 36 individuos, en un sector relativamente pequeño $\left(24 \mathrm{~m}^{2}\right)$, estaría evidenciando la utilización de este espacio como un área específica de inhumaciones (Figura 8), diferenciada de sectores destinados a otro tipo de actividades, como ser áreas de habitación. Por otra parte la elección de un punto específico del paisaje, puede estar indicando aspectos sociales relacionados a la territorialidad (no incluyendo necesariamente el concepto de límite), como así también es probable que los individuos depositados en un determinado sector posean algún vínculo entre sí, relacionado al sistema de linaje (Saxe 1970; Binford 1971, Charles y Buikstra 1983).

Loponte y Acosta (2008) para valores promedios similares de $\delta^{13} \mathrm{C}_{\mathrm{co}}$ al obtenido de los restos de RSC II, mencionan la inclusión en la dieta de plantas $\mathrm{C}_{4}, \mathrm{y}$ de acuerdo al "....contexto ecológico y arqueológico local, solo puede corresponder al consumo de maíz.” (Loponte y Acosta 2008: 158). Si bien para el caso aquí referido, sólo son datos iniciales los que habrá que profundizar con nuevos análisis que aporten a la discusión de las prácticas agrícolas en el área, no deja de ser relevante el valor obtenido que permite pensar en otro tipo de estrategia de subsistencia para el o los grupos que ocuparon el 
área de estudio en el pasado.

\section{Figura 8}

\section{Vista general del área de enterratorios}

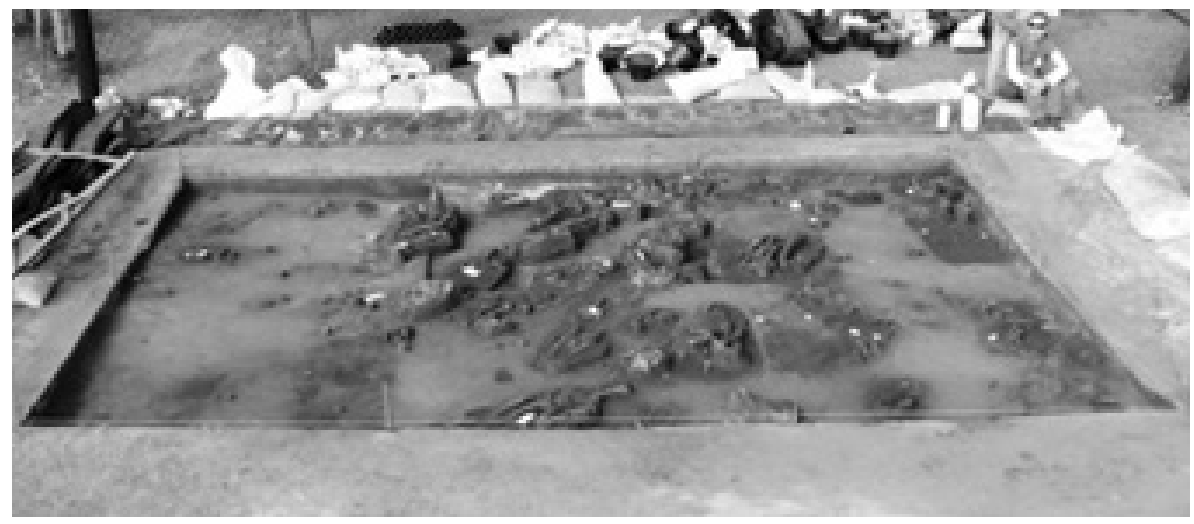

En relación a los materiales cerámicos los datos relevados estarían indicando en términos generales, la producción de vasijas con acabados homogéneos, buena integración de temperantes, $\mathrm{y}$ una tendencia a fracturas regulares la cual es constante en toda la muestra; esta última asociadas a los espectros de colores presentes indican una cocción a temperaturas superiores a $\operatorname{los} 750^{\circ} \mathrm{C}$, donde preponderantemente se dio una circulación libre de oxígeno, provocando la oxidación de las superficies internas y externas, y en algunos casos llegando a oxidar ambos márgenes de las piezas, dando como resultado núcleos reductores, y más escasamente oxidados, probablemente por corto tiempo de exposición al calor. Todas estas características podrían estar evidenciando la utilización de pozos u oquedades que favorecieron la atmósfera de reducción, permitiendo un mejor control de las condiciones de cocción.

Por otra parte es significativa la recurrencia de decoraciones relevadas en los tiestos con bordes, cuya mayoría proviene del contexto de enterratorios humanos, en este sentido cabe la posibilidad de pensar en un uso simbólico o ritual de la cerámica, ya que como se mencionó anteriormente un contenedor fue localizado como ofrenda funeraria. Teniendo en cuenta lo expresado, es posible que los tiestos analizados no estén evidenciando necesariamente la producción de contenedores con fines utilitarios económicos (almacenamiento, cocción de alimentos, transporte de agua, entre otros). Finalmente un punto no mencionado aquí es que en el pozo de sondeo 1, realizado a 10 $\mathrm{m}$ del área de enterratorios se localizó una acumulación de cuentas de cerámica de color rojo, junto con tres de manufactura lítica (Figura 9), lo que demuestra la utilización de la arcilla y la roca, también con fines suntuarios. Estas cuentas no se localizaron asociadas a ningún enterratorio.

La baja representatividad de especímenes faunísticos puede deberse a la funcionalidad específica del sitio que ha sido definido hasta el momento, de acuerdo a 
la evidencia recuperada, como un área de enterratorios múltiples. Por otra parte al estar decapitado el perfil del área no se descarta que se haya perdido material arqueológico con el transcurrir del tiempo. Hasta el momento y como se mencionó anteriormente la incidencia de roedores, raíces, meteorización y acidez del suelo no parecen ser factores de incidencia directa en el estado de la muestra, a diferencia del pisoteo y tránsito vehicular que afectaron los elementos de manera directa.

\section{Figura 9}

\section{Detalle de las cuentas cerámicas y líticas}

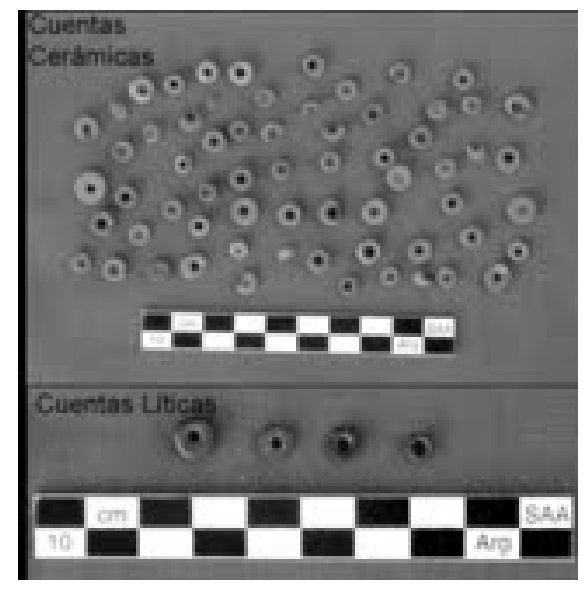

Se considera por los motivos expuestos en el apartado anterior que vinculado a la utilización de la fauna, pueden estar actuando factores de índole cultural en la baja representatividad de la misma; sea porque en los sectores excavados no se llevaron a cabo actividades vinculadas a la utilización de la fauna (esto es preparación de las presas, trozamiento, cuereo, cocción) o que la misma esté representando patrones de conducta vinculados a la esfera simbólica. Tanto los especímenes de peces con presencia de alteraciones térmicas, como las hemimandíbulas de M. coipus de un rango etario acotado -juveniles subadultos- en conjunto con la presencia de espículas carbón y ocre vinculadas al área de enterratorios apoyarían esta idea

La cantidad de enterratorios humanos, y la proximidad de los sitios RSC I y II, sumado a la distribución vertical de los ítems, los cuales se localizan a profundidades recurrentes, permiten pensar que el área por lo menos para el 1000 AP ha estado intensamente poblada, no descartándose la recurrencia de ocupación a través del tiempo, ya que geográficamente se trata de una localización estratégica, no sólo por la altura del terreno, sino por la proximidad de fuente de agua y arcillas como así también la alta visibilidad del paisaje.

La escasa densidad de materiales (223 restos faunísticos, 219 cerámicos y 9 líticos) en 13,23 $\mathrm{m}^{3}$ excavados, puede estar marcando el uso temporario de este lugar mientras se llevaron a cabo las inhumaciones. Esta explicación se ve reforzada 
debido a que de acuerdo al número mínimos de individuos evidenciado en el área de enterratorios -MNI de 36 en 5, $48 \mathrm{~m}^{3}$-, sería esperable localizar en las proximidades del sitio un área de ocupación relacionada a un campamento base con alta variabilidad hacia el interior del sitio, la cual no se localizó al menos hasta el momento de redacción de este trabajo. Por otra parte, la presencia de numerosos enterratorios secundarios, da cuenta de que los individuos contenidos en los mismos, fueron enterrados en otro lugar y luego trasladados al sitio estudiado, lo que marcaría la utilización de otros espacios (cercanos o lejanos indistintamente) por el o los grupos que enterraron en el sitio aquí estudiado, a sus muertos. Teniendo en cuenta lo expresado también se podría pensar a RSCII como un sitio tipo 'field camp', es decir un centro operacional temporario para un grupo de tareas (Binford 1980, 1997) -donde los grupos de tareas comen, duermen y se mantienen durante un período determinado- en este caso relacionado al área de enterratorios múltiples.

Es interesante que los tiestos recuperados presenten un patrón de cocción a altas temperaturas; en relación a esto se propuso anteriormente la utilización de hornos cerrados para la cochura de las vasijas, de los cuales aún no se ha localizado evidencia; de acuerdo al planteo aquí expuesto, una vía de explicación en relación a esta ausencia es que los mismos se encuentren en las zonas de campamento base y no en un sitio de tareas acotadas.

En síntesis se propone a RSC II como área de actividades específicas, donde la evidencia recuperada estaría dando cuenta en cada caso de una ocupación temporaria vinculada al uso del sector como área de enterratorios múltiples.

Cabe destacar que las tareas de excavación no se consideran finalizadas, el área donde se encuentran RSC I y II, es muy amplia y hasta el momento todos los sondeos realizados han sido positivos en cuanto a presencia de materiales arqueológicos. Así mismo al momento de finalización de este escrito, se continúa con las tareas de limpieza y curaduría de elementos óseos humanos, con lo que análisis futuros pueden cambiar los resultados e interpretaciones realizadas en este escrito.

Teniendo en cuenta lo expresado este trabajo es una primera aproximación a la explicación del registro arqueológico analizado hasta el momento para el sitio RSC II.

\section{Agradecimientos}

Los autores desean agradecer los comentarios y sugerencias de los evaluadores, los cuales creemos han enriquecido el presente trabajo. Todo lo vertido es de exclusiva responsabilidad de los autores.

\section{Referencias bibliográficas}

Aschero, C.1983. Registro de Códigos para Atributos Descriptivos Aplicados a Artefactos Líticos. Informe al CONICET. Ms.

Astiz, M. E., A. De Giacomo, A. Koldorf E I.Maldonado. 1975. "Nota preliminar sobre un sitio 
Feuillet Terzaghi y Deluca. Enterratorios múltiples en la cuenca inferior del río Salado

arqueológico en la margen derecha del río Coronda (Provincia de Santa Fe)". En: Actas y Trabajos del Primer Congreso de Arqueología Argentina. Rosario. Tomo I: pp 243-249

Austral, A. Y A. M. Rocchietti. 1995. “Arqueología de la pendiente Oriental de la Sierra de Comechingones". En: Actas del XI Congreso Nacional de Arqueología Argentina. 10a Parte. San Rafael. pp 61-80

Badano, V. M. 1940. "Piezas Enteras de Alfarería del Litoral Existentes en el Museo de Entre Ríos. Notas Arqueológicas II”. En: Memorias del Museo de Entre Ríos 14. Paraná.

Badano, V. M. 1957 "El arte plástico de los ribereños paranaenses". En: Memorias del Museo de Entre Ríos 34 pp 7-178.

Behrensmeyer, A. K.1978. "Taphonomic and Ecologic Information from Bone Weathering". En: Paleobiology 4: pp 150-162.

Berwick, D. E. 1975. "Valoración del análisis sistemático de los restos de fauna en sitios arqueológicos". En: Chungara 5: pp 125-140.

Binford, L.1971. "Mortuary Practices: Their Study and their Potential". En Approaches to the Social Dimensions of Mortuary Practices, J. A. Brown (ed.), Society for American Archaeology, Washington D. C. pp. 6-29

Binford, L.19711980 Willow Smoke and Dog's Tails: Hunter-Gatherer Settlement Systems and Archaeological Site Formation. En: American Antiquity 45(1):pp 4-20.

Binford, L.19711981 Bones: Ancient Men and Modern Myths. Academic Press, New York.

Binford, L.19711997 En Busca del Pasado. Editorial Crítica, Barcelona.

Buikstra, J. E. and D. H. Ubelaker. 1994. Standards for Data Collection from Human Skeletal Remains. Arkansas Archaeological Survey Research Series 44.

Braun, D. P. 1983. "Pots asTools". En Archaeological Hammers and Theories, J. A. Moore and A. S. Keene (eds.),. Academic Press, New York. pp. 107-134

Brooks, S. y J. M. Suchey.1990. "Skeletal Age Determination Based on the Os Pubis: A Comparison of the Ascadi-Nemerski and Suchey-Brooks Methods". En: Journal of Human Evolution 5: pp 227-238.

Carr, C.1995. "Mortuary Practices: Their Social, Philosophical-Religious, Circumstantial, and Physical Determinants". En: Journal of Archaeological Method and Theory 2(2): pp 105-200.

Castellanos, A. 1924. "Contribución al Estudio de la Paleoantropología Argentina. Restos Descubiertos en el Arroyo Cululú (Pcia. de Santa Fe)". En: Revista de la Universidad Nacional de Córdoba 11 pp 70-90.

Castellanos, A. 1944. "Punta de flecha ósea descubierta en el Pampeano Medio del Arroyo Saladillo (Rosario, Santa Fe)”. En: Publicaciones del Instituto de Fisiografía y Geología 22, Rosario.

Ceruti, C. N.1991. Informe de avance Conicet. ms.

Ceruti, C. N.1995a."Reinterpretación de Algunos Sitios Arqueológicos Tempranos en la Provincia de Santa Fe: Cuenca del Salado-Cululú". En: Actas y Memorias del XI Congreso Nacional de Arqueología Argentina (Décimo Quinta Parte) Revista del Museo de Historia Natural de San Rafael, T. XXVII, Mendoza

Ceruti, C. N. 1995b. Distribución de las distintas etnias que habitaron la provincia. Colección 
Cuadernillos: Historia de Santa Fe 1- Poblamiento, Conquista y Colonización. Santa Fe. Cocco, G., M. C. Barboza, M. P. Ayuso y L. Perez Jimeno. 2000. “El Sitio Isla Cementerio: La Interpretación del Registro Arqueológico y su Relación con la Evolución del Paisaje". En: Libro de Resúmenes del II Congreso de Arqueología de la Región Pampeana Argentina. Mar del Plata.

Collins, M. 1990. "Una Propuesta Conductual para el Estudio de la Arqueología Lítica". En: Etnia 34/35: pp 47-65.

Chapman, R.1995. “Ten Years After, Megaliths, Mortuary Practices and Territorial Model”. En: Regional Approaches to Mortuary Analysis. L. Anderson Beck, (ed.),. Plenum Press, New York. pp. 29-51

Charles, D. G. And J. Buikstra.1983. Archaic Mortuary Sites in the Central Mississippi Drainage: Distribution, Structure, and Behavioral Implications. En Archaic Hunters Gatherers in the American Midwest. J. Phillips and J. Brown (eds.),. Academic Press, New York. pp. 114-144

Davis, S. 1989. La arqueología de los animales. Ediciones Bellaterra, Barcelona.

De Aparicio, F.1935. El Paraná y sus Tributarios. Academia Nacional de la Historia. Historia de la Nación Argentina. El Ateneo, Buenos Aires.

De Aparicio, F.1940. "Síntesis Arqueológica". En: Relaciones de la Sociedad Argentina de Antropología II. Buenos Aires.

De Aparicio, F. Y J. Frenguelli.1923. “Los Paraderos de la Margen Derecha del Río Malabrigo (Departamento Reconquista Santa Fe)". En: Anales de la Facultad de Ciencias de la Educación I. Paraná.

Escudero, S.1998. "Evaluación de contexto de depositación en ambientes fluviales. Propuesta y aplicación de un modelo al sitio Bajada Guereño. (Prov. de Santa Fe)". En: Actas XVIII Encuentro de Geohistoria Regional: IIGHI-CONICET. Resistencia pp 165-177

Escudero, C. S. y M. R. Feuillet Terzaghi 2002. "El registro arqueofaunístico del sitio Bajada Guereño (Prov. de Santa Fe). Implicancias en el aprovechamiento de vertebrados". En: Actas XXII Encuentro de Geohistoria Regional. Resistencia. IIGHI-CONICET. Resistencia. pp 166-172

Feuillet Terzaghi, M. R. 2002. El Registro Arqueofaunístico de Vertebrados del Sitio Playa Mansa I (Arroyo Seco, Dpto. Rosario, Pcia. de Santa Fe). Aportes y Perspectivas. Tesis de Licenciatura. Departamento de Arqueología. Escuela de Antropología. Facultad de Humanidades y Artes. Universidad Nacional de Rosario. ms.

Feuillet Terzaghi, M. R. 2004. “Arqueología de la cuenca inferior del Río Salado, (Dpto. La Capital, Pcia. de Santa Fe): Estado actual de las investigaciones". En prensa en $X V$ Congreso Nacional de Arqueología Argentina. Universidad Nacional de Río Cuarto, Río Cuarto.

Feuillet Terzaghi, Ma. Rosario y Escudero, Sandra. 2010. "Viejas y Nuevas: Evidencias de ocupación en el Holoceno Tardío en la cuenca inferior del río Saldo y superior del río Coronda". En: Mamül Mapu: pasado y presente desde la arqueología pampeana. M. Berón, L. Luna, M. Bonomo, C. Montalvo, C. Aranda y M. Carrera Aizpitarte. Ayacucho Libros del Espinillo, Provincia de Buenos Aires:

Feuillet Terzaghi, Ma. Rosario y Escudero, Sandra. 2011. "Estrategias de Subsistencia- 
Feuillet Terzaghi y Deluca. Enterratorios múltiples en la cuenca inferior del río Salado

Asentamiento en Grupos Cazadores-Recolectores del Sur de la Provincia de Santa Fe". En: Arqueología de Cazadores-Recolectores en la Cuenca del Plata. G. Cocco y M. R. Feuillet Terzaghi Compiladores. Centro de Estudios Hispanoamericanos, Provincia de Santa Fe.

Frenguelli, J.1920. "Excursión a los Alrededores de Esperanza". En: Boletín de la Academia Nacional de Ciencias de Córdoba XXIV:.Cordoba. pp 257-292

Gifford, D.P. 1981. "Taphonomy and Paleoecology: A Critical Review of Archaeology's Sister Disciplines". En: Advances in Archaeological Method and Theory, 4: pp 365-438.

González, M. I. 2005. Arqueología de alfareros, cazadores y pescadores pampeanos. Colección Tesis Doctorales. Sociedad Argentina de Antropología, Buenos Aires.

Gollan, J. Y D. Lachaga. 1939. Aguas de la Provincia de Santa Fe. Santa Fe.

Grayson, D. K. 1984. Quantitative Zooarchaeology. Topics in the Analysis of Archaeological Faunas. Academic Press, Orlando.

Hocsman, S. 1999. "Aprovisionamiento de materias primas líticas en el Paraná Medio prehispánico". En: En los Tres Reinos: Prácticas de Recolección en el Cono Sur de América. Instituto de arqueología y Museo Facultad de Ciencias Naturales, U.N. de Tucumán, Tucumán.

Iriondo, M. 1991. "El Holoceno en el Litoral”. En: Comunicaciones del Museo Provincial de Ciencias Naturales "Florentino Ameghino" 3: pp 1-39.

Johnson, E. 1985. Current Development in Bone Technology. En: Advances in Archaeological Method and Theory 8: pp 157-235.

Klein, R. And K. Cruz Uribe.1984. The Analysis of Animal Bones from Archaeological Sites. The University of Chicago Press, Chicago.

Larguía de Crouzeilles, A. 1936. "Datos Arqueológicos Sobre Paraderos Indígenas de Santa Fe (Isla del Periquillo, Helvecia y Sauce Viejo)". En: Anales de la Sociedad Cientifica Argentina CXXII: pp 326- ss.

Larguía de Crouzeilles, A. 1939. "Correlaciones entre la alfarería indígena encontrada en la región de Santa Fe y la de la provincia de Santiago del Estero". En: Anales de la Sociedad Cientifica Argentina IV(CXXVIII):. (Tirada Aparte). Pp 196- ss

Loponte, D. Y A. Acosta. 2008. "El Registro Arqueológico del Tramo Final de la Cuenca del Plata”. En: Entre la Tierra y el Agua: Arqueología de los Humedales de Sudamérica. D. Loponte y A. Acosta (Comps.), Asociación Amigos del Instituto Nacional de Antropología y Pensamiento Latinoamericano (AINA). pp. 125-164.

Lyman, L. 1984. "Broken bones, bone expediency tools, and bone pseudotools: Lessons from the blast zone around Mount St. Helens, Washington". En: American Antiquity 49(2): pp315-333.

Lyman, L. 1994. Vertebrate Taphonomy. Cambridge University Press, Cambridge.

Lyman, L.. 2002. “Taphonomic Agents and Taphonomic Signatures”. En: American Antiquity 67(2): pp 361-366.

Letieri, F.1999. “Análisis tecnocomparativo del material cerámico arqueológico en el extremo oriental del Área con Paleocauces Enterrados de la provincia de Santa Fe". En: Actas del XIX Encuentro de Geohistoria Regional. Corrientes. 
Ottalagano, F. 2002. "Consideraciones sobre la aplicabilidad de la arqueología conductual al estudio cerámico en la llanura aluvial actual y antigua del Paraná (sector santafesino)". En : Libro de Resúmenes del III CARPA, UNCPB, Olavarría.

Outes, F.1917. "Nuevo jalón septentrional en la dispersión de las representaciones plásticas de la cuenca paranaense y su valor indicador". En: Anales de la Sociedad Cientifica Argentina LXXXV:. Buenos Aires pp 53-66

Outes, F.1923. "Las representaciones plásticas de la cuenca pararanaense. A propósito de una crítica". En: Revista de la Universidad de Buenos Aires LI.

Pérez Jimeno, L.1999. “Zooarqueología del sitio Barrancas del Paranacito. Florencia, Depto. Gral. Obligado (Prov. de Santa Fe)". En: Libro de resúmenes del XIII CNAA. Cabildo Histórico de la Ciudad de Córdoba. Córdoba.

Pérez Jimeno, L. 2002. “Análisis comparativo de dos conjuntos de artefactos óseos procedentes de la llanura aluvial del Paraná y la pampa bonaerense”. En: Libro de Resúmenes del III CARPA, UNCPB, Olavarría.

Prehistoric Ceramics Research Group 1995. "The study of later prehistoric pottery: general policies and guidelines for análisis and publication”. En: Occasional papers 1 and 2. England.

Rusconi, C. 1930. "Evolución craneodental de la nutria (Myocastor coypus bonariensis) a través de su desarrollo postembrionario". En: Anales de la Sociedad Cientifica Argentina 110: pp 5-31.

Salemme, M., L. Miotti y E. Tonni 1988. "La Determinación Sistemática de Mamíferos en el Análisis Arqueofaunístico". En: De Procesos, Contextos y Otros Huesos. N. Ratto y A. Haber (ed.), ICA Sección Prehistoria, FFyL. UBA, Bs. As. pp. 65-73.

Santiago, F.2002. Los Roedores en el Menú de los Habitantes del Sitio Cerro Aguará. Florencia Provincia de Santa Fe. Tesis de Licenciatura. Departamento de Arqueología. Escuela de Antropología. Facultad de Humanidades y Artes. Universidad Nacional de Rosario. ms.

Sartori, J. 2008. La Cuenca Inferior del Río Salado: Un Desafio para los Análisis Arqueofaunísticos. Tesis de Licenciatura. Departamento de Arqueología. Escuela de Antropología. Facultad de Humanidades y Artes. Universidad Nacional de Rosario. $m s$.

Sartori, J. y M. R. Feuillet Terzaghi 2007. "El Registro Arqueológico del Sitio Río SaladoCoronda. Dpto. La Capital Pcia. de Santa Fe". Actas del XXVI Encuentro de Geohistoria Regional (Resistencia 2006) IIGHI-CONICET. Resistencia. pp 496-502.

Saxe, A. A. 1970 Social Dimensions of Mortuary Practices. Ph. D. Dissertation, University of Michigan. University Microfilms No 71-04720.

Schiffer, M. B. And J. M. Skibo.1997. “The Explanation of Artifact Variability”. American Antiquity 62(1): pp 27-50.

Serrano, A. 1922. “Arqueología de las Tejas”. En: Revista Universitaria del Litoral 12: pp 1571.

Serrano, A. 1929. "El área de dispersión de las llamadas alfarerías gruesas del territorio argentino". En: Physis 10: pp.1-9.

Serrano, A. 1931. “Arqueología del Litoral”. Memorias del Museo de Paraná 4.. Paraná. pp. $1-26$ 
Feuillet Terzaghi y Deluca. Enterratorios múltiples en la cuenca inferior del río Salado

Serrano, A. 1954. "Contenido e Interpretación de la Arqueología Argentina. El Área Litoral”. Universidad, Revista de la Universidad Nacional del Litoral 29:. Santa Fe. Pp 1-29

Serrano, A. 1972. Líneas Fundamentales de la Arqueología del Litoral (Una tentativa de Periodización. Instituto de Antropología. Córdoba.

Skibo, J. M.1992. Pottery function. A Use-alteration Perspective. Plenum Press, New York.

Torres, L. M. 1907. “Arqueología de la Cuenca del Río Paraná”. Revista del Museo de La Plata XIV: pp 53-122.

Ubelaker, D. H. 1989. Human Skeletal Remains: Excavation, Analysis, Interpretation. Taraxacum, Washington D. C.

Vignati, M. A. 1923. "Nota sobre el hombre fósil del Arroyo Cululú, Provincia de Santa Fe". Physis (7):. Buenos Aires. pp 62-65

Vignati, M. A.1925-27. “Un vestigio de la queratotecnia del hombre fósil de Esperanza”. Physis (8):. Buenos Aires. pp 242-249

White, T. D. And A. F. Folkens 2000. Human Osteology. Second Edition. Academic Press. San Diego.

Wood, W. y D. Johnson. 1978. "A Survey of Disturbance Processes in Archaeological Site Formation". En: Advances in Archaeology Method and Theory. M. Schiffer (ed.), Academic Press, New York. pp 539-601

Zapata Gollan, A. 1989. Caminos de la Colonia. Obra Completa. Centro de Publicaciones. Universidad Nacional del Litoral. Santa Fe. 